Oral presentation

\title{
The multifactorial approach: a case study Michalis Athitakis
}

Address: Open Psychotherapy Centre, Athens, Greece

from International Society on Brain and Behaviour: 3rd International Congress on Brain and Behaviour

Thessaloniki, Greece. 28 November - 2 December 2007

Published: 17 April 2008

Annals of General Psychiatry 2008, 7(Suppl I):S7 doi:I0.I186/1744-859X-7-SI-S7

This abstract is available from: http://www.annals-general-psychiatry.com/content/7/SI/S7

(c) 2008 Athitakis; licensee BioMed Central Ltd.

In this presentation, a case study which was treated through the multifactorial appoach (Dyadic Therapy, Therapeutic Community, Group Analysis, Family Therapy, Pharmachotherapy) is presented. The above study case illustrates the dynamics which have arisen in this kind of multi level approach, as well as the resulting potientialities for more effective therapeutic interventions. The effectiveness of the approach is also discussed. 